\title{
Anti-Tumor Activity of Docetaxel PLGA-PEG Nanoparticles with a Novel Anti-HER2 scFv
}

\author{
Duong Thi Thuy Le ${ }^{1 *}$, Lua Thi Minh Dang ${ }^{1}$, Nhung Thi My Hoang ${ }^{2}$, Huyen Thi La ${ }^{1}$, Huyen Thi Minh Nguyen ${ }^{1}$ and Huan Quang Le ${ }^{1}$ \\ ${ }^{1}$ Department of Animal Cell Technology, Institute of Biotechnology, Vietnam Academy of Science and Technology, 18 Hoang Quoc Viet Road, Cau Giay District, Hanoi, \\ Vietnam
}

${ }^{2}$ Department of Cell Biology, Faculty of Biology, Hanoi University of Sciences, Viet Nam National University, 334 Nguyen Trai Road, Thanh Xuan District, Ha Noi, Vietnam

\begin{abstract}
Background: In this study, we developed pegylated (poly D,$L_{\text {-lactide-co-glycolide) (PLGA-PEG) nanoparticles }}$ for loading docetaxel and improving active target in cancer cells because it's advantages over other nanocarriers such as excellent biocompatibility, biodegradability and mechanical strength and these nanoparticles were conjugated with molecules of a novel anti-HER2 single chain fragment (scFv) by a simple carbodiimide modified method. ScFvs have potential advantages over whole antibodies such as more rapid tumor penetration and clearance. In addition, to investigate cellular uptake of targeted nanocarriers, many studies had performed by linking with fluorescent factors but in this study 6-histidine-tag fused with novel anti-HER2 ScFv antibodies can be used to purify protein and study binding activity and cellular uptake of targeting nanoparticles that it was not changed their characterization in vitro. Furthermore, cytotocixity of these nanoparticles was also investigated in BT474 (HER2 overexpress) and MDA-MB-231 (HER2 underexpress) cells.
\end{abstract}

Results: Docetaxel loaded nanoparticles (Doc-NPs) with a mean size of $105 \mathrm{~nm}$ and zeta potential of $-25 \mathrm{mV}$ were prepared by nanoprecipitation method. Conjugation of a novel single chain fragment of antibody against epidermal growth factor receptor 2 to Doc-NPs by covalent coupling via cross-linker EDC and NHS resulted in an increase of mean size and zeta potential of targeted nanoparticles (scFv-Doc-NPs) with $135 \mathrm{~nm}$ and $-32 \mathrm{mV}$ respectively. The scFvDoc-NPs bound specifically to BT474 cells but no MDA-MB-231 cells was investigated by flow cytometry. Especially, confocal fluorescence scanning microscopy revealed internalization of the scFv-Doc-NPs by the targeted cancer cells through anti-Histag antibodies with Alexa Fluor ${ }^{\circledR} 546$. Moreover, the scFv-Doc-NPs showed stronger cytotoxicity on BT474 cells than MDA-MB-231 cells with $\mathrm{IC}_{50}$ values of 0.234 and $0.535 \mu \mathrm{M}$, respectively.

Conclusion: Here we report anti-HER2 scFv labeled and docetaxel loaded PLGA-PEG nanoparticles in order to broaden the applications of this new targeted drug delivery system in the therapy of HER2 overexpressed cancers. Also, this drug delivery system represents a promising approach to improve the efficacy of nanoparticles in active targeting for HER2-overexpressed cancer therapy.

Keywords: Active targeting; Docetaxel; scFv; Polymeric nanoparticles; anti-HER2

\section{Background}

Chemotherapy has much side effects because of nonspecific biodistribution of chemotherapeutic agents. Many nanoparticle drug delivery systems have been designed to improve the efficacy of anticancer agents, minimize side effects and to enhance biocompatibility, serum stability [1]. Moreover, to improve more effect of nanoparticle drug delivery, the surface modification of nanoparticles with peptides, nucleic acids, antibodies, aptamers, or small molecules that bind to antigens on the surface of cancer cells or cancer tissues may be considered as an efficiently targeted delivery of cancer drugs [2]. Human epidermal growth factor receptor 2 (HER-2/neu) is one of the major targets for the design of targeted anticancer drugs and monoclonal antibodies specific to certain antigens on the surface of cancer cells have been used most often for the targeting of nanoparticles to tumor sites [3]. This HER$2 /$ neu receptor is a $185-\mathrm{kDa}$ transmembrane glycoprotein encoded by HER2 or the c-erbB-2 proto-oncogene on chromosome $17 \mathrm{q} 21$ belonging to the EGFR family. It has three domains: an extracellular domain (EDC), a hydrophobic transmembrane region, and an intracellular tyrosine kinase domain. The ligand-binding portion of the receptor is EDC [4,5]. Overexpression of HER-2/neu protein is detected in many tumors including invasive breast, colorectal, ovarian, pancreatic, stomach and prostate cancers... [6-9].

For $\mathrm{scFv}$, it has advantages over whole antibodies such as greater tumor penetration, lower retention in non-target tissues, more rabid blood clearance, and less immunogenic response in vivo [10]. These antibody fragments have been widely used as targeting moieties of nanocarriers both in vitro [11] and in vivo [12] and are particularly attractive because their binding properties can readily be engineered using directed evolution [13].

Moreover, conjugation of different polymers with chemotherapeutic drugs in order to formulate various nanocarriers have been studied throughout the last decates and have improved safety and efficacy of drugs $[14,15]$. Especially, PLGA has generated tremendous interest due to its excellent biocompatibility, biodegradability, and mechanical strength [16]. Also, PLGA molecules have hydrophobic nature, therefore hydrophobic drugs, including most anticancer agents, can

*Corresponding author: Duong Thi Thuy Le, Department of Animal Cell technology, Institute of Biotechnology, Vietnam Academy of Science and Technology, 18 Hoang Quoc Viet Road, Cau Giay District, Hanoi, Vietnam, Tel: 84-1668661637; E-mail: thuyduongbio@yahoo.com

Received October 20, 2014; Accepted January 28, 2015; Published February 08, 2015

Citation: Le DTT, Dang LTM, Hoang NTM, La HT, Nguyen HTM, et al. (2015) AntiTumor Activity of Docetaxel PLGA-PEG Nanoparticles with a Novel Anti-HER2 scFv. J Nanomed Nanotechnol 6: 267. doi:10.4172/2157-7439.1000267

Copyright: ( 2015 Le DTT, et al. This is an open-access article distributed under the terms of the Creative Commons Attribution License, which permits unrestricted use, distribution, and reproduction in any medium, provided the original author and source are credited. 
be easily loaded into PLGA nanoparticles [17]. It has also been used by many researchers for passive and active targeting of anticancer agents [18]. Moreover, water-soluble shell around the particle was be able to prevent attachment of plasma proteins [19]. Therefore, PLGA nanoparticles coated PEG results in highly stable drug delivery system and PEG has been used in FDA-approved biotherapeuticals [20]. PEG on the surface of nanoparticles reduced recognition and clearance and prolonged blood circulation time of nanoparticles [21]. Recent studies have used PLGA-PEG to load anti-cancer drugs [22,23] and to formulate targeting drug delivery systems [24-26]. However, no study has investigated PLGA-PEG nanoparticles with anti-HER2 scFv antibodies. Moreover, to produce targeting drug delivery systems conjugated with antibodies, it need to go through multiple steps [27-29]. This may affect the targeted drug delivery and the activity of antibodies. In this report, we use carbodiimide method and a modification with simple steps, therefore targeted docetaxel delivery conjugated with anti-HER2 scFv have good activity for targeted cancer cells.

Docetaxel is a leading chemotherapeutic drug for breast carcinoma, ovarian, head and neck, and lung cancer [30-32]. In this study, we report on a conjugation of polymer and novel anti-HER2 monoclonal antibodies with their most advantages in the preparation and characterization of pegylated PGLA nanoparticles as a targeted delivery system for docetaxel. In addition, to investigate cellular uptake of targeted nanocarriers, many studies had performed by linking with fluorescent factors [33-35] but in this report 6-histidine-tag fused with novel anti-HER $2 \mathrm{scFv}$ antibodies can be used to study binding activity and cellular uptake in vitro. Their ability to target and enter Her2overexpressed BT-474 cells was studied and compared with MDAMB-231 cells as a negative control.

\section{Materials and Methods}

\section{Materials}

Docetaxel anhydrous (Doc) of purity was purchased from Shanghai Bioman Pharma Co. Ltd, Shanghai, China. Poly $\left(_{D_{-}^{-}}\right.$ lactide-co-glycolide) with terminal carboxylate groups (PLGA, lactide:glycolide, 50:50, Mw 7000 - 1700), bifunction poly(ethylene glycol 2-aminoethyl ether acetic acid ( $\mathrm{NH}_{2}$-PEG-COOH, $\mathrm{Mw} \sim 3400$ ), 1-Ethyl-3-(3-dimethyllaminopropyl) carbodiimide (EDAC) and $\mathrm{N}$-hydroxysuccimide (NHS) were obtained from Sigma-Aldrich (St Louis, MO). Molecular and cellular biology buffers were purchased from Sigma. 4-Aminobenzoic acid p-aminobenzoic acid and 3-(4,5dimethylthiazol-2-yl)-(2,5-diphenyl tetrazolium bromide) (MTT) was purchase from Promega (US). Monoclonal mouse anti-hexahistidine antibody was purchased from Abcam (Cambridge, MA), anti-mouse secondary antibodies conjugated with Alexa 546 were purchased from Santa Cruz Biotechnologies (Santa Cruz, CA). All other organic solvents were analytical grade from Fisher Scientific.

\section{Cell culture}

Human breast cancer cell lines BT474 (HER2-overexpress) and MDA-MB-231 (HER2-underexpress) (American Type Culture Collection) were obtained from Institute of Biotechnology (VAST). The cell lines were cultivated in DMEM medium supplemented with $10 \%$ fetal bovine serum and $1 \%$ penicillin-streptomycin at $37^{\circ} \mathrm{C}$ in a humidified incubator with $5 \% \mathrm{CO}_{2}$. The cells were maintained in an exponential growth phase by periodic subcultivation.

\section{Synthesis of PLGA-PEG}

Copolymer PLGA-PEG was synthesized by conjugation of $\mathrm{NH}_{2}$ -
PEG-COOH to PLGA-COOH. Briefly, $150 \mathrm{mg}$ of PLGA-COOH were dissolved in $1 \mathrm{ml}$ DCM. PLGA-carboxylate was converted into PLGANHS by adding $1 \mathrm{mg}$ of NHS and $2 \mathrm{mg}$ of EDAC in $1 \mathrm{ml}$ DCM with gentle stirring. PLGA-NHS obtained was precipitated with $10 \mathrm{ml}$ ethyl ether/methanol washing solvent by centrifugation at $3000 \mathrm{rpm}$ for 10 min and the washing process was repeated two times to remove residual EDC/NHS. The PLGA-NHS pellet was dried under vacuum for $30 \mathrm{~min}$ to remove residual ether and methanol. After drying under vacuum, $100 \mathrm{mg}$ of PLGA-NHS was dissolved in $2 \mathrm{ml}$ DCM followed by addition $10 \mathrm{mg}$ of $\mathrm{NH}_{2}$-PEG-COOH and $7.5 \mathrm{mg}$ of $\mathrm{N}, \mathrm{N}$-diisopropylethylamine. The mixture solution was incubated for $24 \mathrm{~h}$ at room temperature under gentle stirring. Then, this mixture washed by ether/methanol washing solvent and centrifuged to remove unreacted PEG. The resulting PLGAPEG copolymer was dried under vacuum and used for nanoparticle preparation without further treatment. The following are the main nuclear magnetic resonance (NMR) peaks of the sample:

${ }^{1} \mathrm{H}-\mathrm{NMR}\left(\mathrm{CDCl}_{3}\right.$ at $\left.500 \mathrm{~Hz}\right) \mathrm{d} 5.2\left(\mathrm{~m},\left(\mathrm{OCH}\left(\mathrm{CH}_{3}\right) \mathrm{C}(\mathrm{O}) \mathrm{OCH}_{2} \mathrm{C}(\mathrm{O})\right.\right.$ $\left.\mathrm{n}-\left(\mathrm{CH}_{2} \mathrm{CH}_{2} \mathrm{O}\right) \mathrm{m}\right), 4.8\left(\mathrm{~m},\left(\mathrm{OCH}\left(\mathrm{CH}_{3}\right) \mathrm{C}(\mathrm{O}) \mathrm{OCH}_{2} \mathrm{C}(\mathrm{O}) \mathrm{n}-\left(\mathrm{CH}_{2} \mathrm{CH}_{2} \mathrm{O}\right)\right.\right.$ $\mathrm{m}), 3.7\left(\mathrm{~s}, \quad\left(\mathrm{OCH}\left(\mathrm{CH}_{3}\right) \mathrm{C}(\mathrm{O}) \mathrm{OCH}_{2} \mathrm{C}(\mathrm{O}) \mathrm{n}-\left(\mathrm{CH}_{2} \mathrm{CH}_{2} \mathrm{O}\right) \mathrm{m}\right), 1.6(\mathrm{~d}\right.$, $\left(\mathrm{OCH}\left(\mathrm{CH}_{3}\right) \mathrm{C}(\mathrm{O}) \mathrm{OCH}_{2} \mathrm{C}(\mathrm{O})\right) \mathrm{n}-\left(\mathrm{CH}_{2} \mathrm{CH}_{2} \mathrm{O}\right) \mathrm{m}$.

\section{Preparation of docetaxel-loaded PLGA-PEG nanoparticles}

The Doc encapsulated PLGA-PEG copolymer nanoparticles were prepared using nanoprecipitation method. Briefly, $10 \mathrm{mg}$ of PLGA-PEG copolymer and $1 \mathrm{mg}$ of Doc were dissolved in acetone. The mixtures were poured into Millipore water solution with the solvent:water $=1: 5$. Nanoparticles were formed immediately, and gently stirred at room temperature (RT) for 4-5 hours to evaporate the organic solvent. The resulting nanoparticle suspension was then collected by ultrafiltration. The nanoparticles were then freeze- dried using the Thermo Electron's Modulyo freeze dryer (USA) for $8 \mathrm{~h}$.

\section{Characterization of docetaxel-loaded PLGA-PEG nanoparticles}

Size and zeta potential measurements: The average size and polydispersity of nanoparticle derivetives were analyzed by dynamic light scattering (DLS). Zeta potential of NPs was evaluated in deionized water $(\sim 1 \mathrm{mg} / \mathrm{ml})$ using the electrophoretic mode of Zetasizer $3000 \mathrm{HS}$ (Malvern instruments Ltd., United Kingdom) at $25^{\circ} \mathrm{C}$. Each sample was measured in triplicate.

Surface morphology: Transmission electron microscopy (TEM) system (Jeol JEM-1010, USA) were used to determine the shape and surface morphology of nanoparticles produced.

Drug encapsulation efficiency: The docetaxel entrapped in the DocNPs and measured by NanoDrop 1000 spectrophotometer (Thermo Fisher Scientific) and quantified by UV-Vis spectrophotometer at 275 $\mathrm{nm}$ for Doc was previously described [45]. Briefly, $3 \mathrm{mg}$ nanoparticles were dissolved in $2 \mathrm{ml}$ of DCM (dichloromethane). DCM was evaporated in nitrogen atmosphere and residue was resuspended in dimethyl sulfoxide (DMSO) for analysis by UV-Vis spectrophotometer. The standard curve of Doc was linear in the range of $50-1000 \mu \mathrm{g} / \mathrm{ml}$ in DMSO. The encapsulation efficiency of Doc was measured by the amount of Doc encapsulated comparing with the total amount of drug used in formulation, multiplied by 100 .

\section{Production and purification of soluble scFv}

For the production and purification, the anti-HER $2 \mathrm{scFv}$ protein was previously expressed in E. coli strain BL21 [42]. Briefly, the fusion gene of anti-Her2 scFv containing $\mathrm{His}_{6}$-tag was cloned into a T7 
promoter-based E. coli expression vector, pET-22b(+). E.coli bacterial cultures were grown at $37^{\circ} \mathrm{C}$ in lysogeny broth (LB) growth medium. The anti-Her2 scFv expression was induced by addition of $0.5 \mathrm{mM}$ isopropyl- ${ }_{\mathrm{L}}$-thio- $\beta_{-}{ }_{\mathrm{D}}$-galactopyranoside (IPTG) and grown to log phase $\left(\mathrm{A}_{600 \mathrm{~nm}}=0.8\right)$. The cells were harvested, centrifuged, and the pellet was resuspended in lysis buffer $\left(20 \mathrm{mM} \mathrm{NaH}_{2} \mathrm{PO}_{4}, 500 \mathrm{mM} \mathrm{NaCl}, 8\right.$ $\mathrm{M}$ Urea) and sonicated on ice when the solution became translucent. The lysate was then centrifuged at $12,000 \mathrm{~g}$ for $30 \mathrm{~min}$ at room temperature. The supernatant was used for purification of $\mathrm{His}_{6}$-tagged protein on HisPrep FF 16/10 column (GE Healthcare Life Sciences) under denaturing conditions using FPLC equipment. The protein was refolded on the column by washing with a linear gradient from 8 to $0 \mathrm{M}$ urea and eluted with $250 \mathrm{mM}$ imidazole. For final purification of antiHer $2 \mathrm{scFv}$, elution fractions were collected by Centrifugal Devices (Pall Life Science, USA). SDS/PAGE analysis of the proteins was performed according to standard protocols using $12.5 \%$ polyacrylamide gels.

\section{Conjugation of scFv to nanoparticles}

The conjugation of anti-HER2 scFv to Doc-NPs was accomplished via crosslinking of $-\mathrm{COOH}$ and $-\mathrm{NH}_{2}$ using carbodiimide method. Briefly, $1 \mathrm{ml}$ of Doc-NPs solution $(2 \mathrm{mg} / \mathrm{ml})$ was incubated with 100 $\mu \mathrm{l}$ of $4 \mathrm{mM}$ EDC and $100 \mu \mathrm{l}$ of $10 \mathrm{mM}$ NHS for 15 minutes at room temperature with gentle stirring. Then the activated particles were covalently linked to $100 \mu \mathrm{l} \mathrm{of} \mathrm{scFv}(1 \mathrm{mg} / \mathrm{ml})$ for 2 hours at room temperature and gently vortex. The reaction mixture was quenched by adding hydroxylamine (to give a final concentration of 5 to 10 $\mathrm{mM}$ ). The Doc-NPs conjugated with anti-Her2 scFv was purified from unconjugated protein and by-products by ultrafiltration. The NPs suspensions were kept at $4^{\circ} \mathrm{C}$ until use.

\section{Flow Cytometry}

Flow cytometry (FCM) was used to evaluate binding of scFvDoc-NPs to target (HER2-overexpress BT474) and nontarget (HER2underexpress MDA-MB-231) cells. Cells were collected from culture and centrifuged for $5 \mathrm{~min}$ at $4^{\circ} \mathrm{C}$ and $1500 \mathrm{rpm}$. Cells were then incubated with $100 \mu \mathrm{g} / \mathrm{ml}$ of Doc-NPs or scFv-Doc-NPs solution for $30 \mathrm{~min}$ at RT. Samples were then washed 3 times with PBS $1 \times$ and were incubated with monoclonal mouse anti-hexahistidine antibodies for 1 $\mathrm{h}$ at RT. After that, samples were washed 2 times by PBS $1 \times$. Samples were incubated with Alexa Fluor ${ }^{\circledR} 546$ goat anti-mouse antibodies for $1 \mathrm{~h}$ at RT and were washed 2 times by PBS $1 \times$ and supernatant was discarded. Then, $500 \mu$ of PBS $1 \times$ was added to each sample, and flow cytometric analysis was performed on FACSCanto II Cytometer (BD Biosciences) with BD FACSDiva ${ }^{\mathrm{TM}}$ software.

\section{Cellular uptake studies}

The cellular uptake of Doc-NPs and scFv-Doc-NPs by cells was observed by fluorescence microscopy. BT474 and MDA-MB-231 cells were allowed to adhere to glass coverslips in 12-well plate for $24 \mathrm{~h}$ before experiments. The cells were then incubated with $100 \mu \mathrm{g} / \mathrm{ml}$ of Doc-NPs or scFv-Doc-NPs for $1 \mathrm{~h}$ at $37^{\circ} \mathrm{C}$. After washing twice with PBS, samples were incubated with monoclonal mouse anti-hexahistidine primary antibody for $1 \mathrm{~h}$ at $4^{\circ} \mathrm{C}$ and then samples were washed three times by PBS $1 \times$. Samples were incubated with Alexa Fluor ${ }^{\circledR} 546$ goat anti-mouse secondary antibody for $1 \mathrm{~h}$ at RT and washed by PBS $1 \times$ three times. Nucleus was counterstained with Hoechst, the cells were fixed with $4 \%$ formaldehyde for $10 \mathrm{~min}$ and analyzed by confocal fluorescence scanning microscopy (Zeiss LMS 510 confocal microscopy).

\section{In vitro cytotoxicity assays}

The in vitro cytotoxicity of the following docetaxel formulations was tested on BT474 and MDA-MB-231 cells using the MTT test: DocNPs, scFv-Doc-NPs, and free docetaxel. Unloaded nanoparticles were used as a control. BT474 and MDA-MB-231 cells were first grown in 96-well plates at the density of $5 \times 10^{3}$ viable cells/well and incubated for 24 hours to allow cell attachment. The medium was replaced by 100 $\mu \mathrm{l}$ of the formulation at different concentrations of $0.05-5 \mu \mathrm{M}$ followed by incubation for $72 \mathrm{~h}$ at $37^{\circ} \mathrm{C}$. For free docetaxel, a stock solution was prepared in DMSO (1M Docetaxel). The DMSO concentration in the medium was lower than $0.5 \%$, at which level it has no effect on cell proliferation. The cell viability was detected by MTT assay (Promega, US) according to manufacturer's instruction. Each assay was repeated three times. Cell viability was calculated using the following equation:

Cell viability $(\%)=\left(\mathrm{Int}_{\mathrm{s}} / \mathrm{Int}_{\text {control }}\right) \times 100(1)$

Where Int $\mathrm{s}_{\mathrm{s}}$ is the colorimetric intensity of cells treated with the samples, and Int ${ }_{\text {control }}$ is the colorimetric intensity of cells treated with the DMEM medium only. All experiments were repeated thrice

\section{Results and Discussion}

\section{Synthesis of PLGA-PEG polymer}

Carboxyl-functionalized PLGA-PEG copolymer was synthesized by direct conjugation of PLGA-COOH with $\mathrm{NH}_{2}$-PEG-COOH, both having fixed block length, to generate PLGA-PEG. The basic chemical structure of PLGA-PEG copolymer was confirmed by ${ }^{1} \mathrm{H}-\mathrm{NMR}$ (Figure1). One of the prominent features is a peak at $3.4 \mathrm{ppm}$, matching the methylene groups of PEG. Overlapping doublets at $1.6 \mathrm{ppm}$ are attributed to the methyl groups of the $\mathrm{D}$ - and L-lactic acid repeat units. The multiples at $5.2 \mathrm{ppm}$ and $4.8 \mathrm{ppm}$ correspond to the lactic acid $\mathrm{CH}$ and the glycolic acid $-\mathrm{CH}$, respectively, with the high complexity of the peaks resulting from different D-lactic, L-lactic glycolic acid sequences in the polymer backbone. The carboxyl group located at the end terminal of the hydrophilic PEG block is available for surface chemistry on the nanoparticle surface.

\section{Characterization of nanoparticles}

Docetaxel was encapsulated in the pegylated PLGA nanoparticles with carboxyl end groups by the nanoprecipitation method. The physicochemical characteristics of the nanoparticles are summarized in table 1.

One of the most important characteristic of nanoparticle systems is their size and size distribution. The biodistribution, toxicity, and targeting ability of these systems is determined by their size. Pore sizes
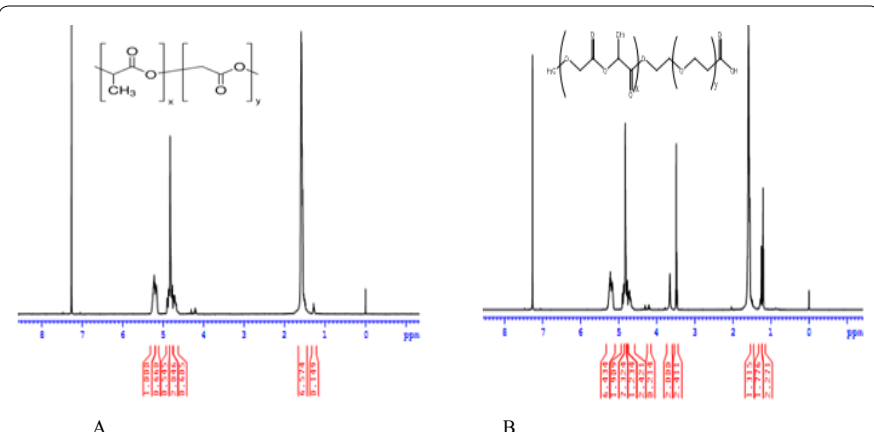

Figure 1: ${ }^{1} \mathrm{HNMR}$ characterization of PLGA-COOH $(\mathrm{A})$ and PLGA-PEG (B) PLGA: $\delta 5.2\left(\mathrm{~m}, \quad\left(\left(\mathrm{OC} \underline{\mathrm{H}}\left(\mathrm{CH}_{3}\right) \mathrm{C}(\mathrm{O}) \mathrm{OCH}_{2} \mathrm{C}(\mathrm{O})\right)_{n}\right)\right) ; \delta 4.8\left(\mathrm{~m}, \quad\left(\left(\mathrm{OCH}\left(\mathrm{CH}_{3}\right)\right.\right.\right.$ $\left.\left.\left.\mathrm{C}(\mathrm{O}) \mathrm{OC} \underline{H}_{2} \mathrm{C}(\mathrm{O})\right)_{\mathrm{n}}\right)\right) ; \delta 1.6\left(\mathrm{~d},\left(\left(\mathrm{OCH}\left(\mathrm{CH}_{3}\right) \mathrm{C}(\mathrm{O}) \mathrm{OCH}_{2} \mathrm{C}(\mathrm{O})\right)_{n}\right)\right.$. PEG: $\delta 3.7$ (s, $\left.\left(\mathrm{C}_{2} \mathrm{C}_{2} \mathrm{O}\right) \mathrm{m}\right)$ 
in tumor microvasculature vary between $100 \mathrm{~nm}$ and $780 \mathrm{~nm}$ [36]. Many studies have recognized the suitable size of these carriers for extravasation and accumulation in solid tumors below $400 \mathrm{~nm}$ [37]. As shown in table 1 and figure 2, the nontargeted nanoparticles had a size of $105 \pm 4 \mathrm{~nm}$ (Figure 2B), whereas the monoclonal antibodytargeted nanoparticles were larger at $135 \pm 9 \mathrm{~nm}$ (Figure 2C) and the drug-unloaded and nontargeted nanoparticles had the smallest mean size of $87 \pm 8$ (Figure 2A). Conjugation may be a reason for the larger size of the targeted nanoparticles [38]. Transmission electron microscopy showed that the nanoparticles and targeted nanoparticles were spherical and rather homogeneous in size (Figure 2).

For nanoparticles and monoclonal antibody-targeted nanoparticles, the zeta potential was $-24 \pm 0.3 \mathrm{mV}$ and $-32 \pm 1 \mathrm{mV}$, respectively. This result shows that the negative value of mean zeta potential of the targeted nanoparticles is increased due to coupling of anti-HER2 scFv to the nanoparticles, containing several ion groups and suggesting that conjugation of monoclonal antibodies to the nanoparticles leads to an increase in the negative surface charge of targeted nanoparticles.

Previous studies have shown that in order to release taxane drugs at a sustainable rate from PLGA NPs, the drug loading concentrations should be limited [39], especially in the case of pegylated NPs [40]. Therefore, NPs containing variable amounts of docetaxel were synthesized by adjusting docetaxel drug loading at $10 \%$ by weight of the added polymer and it was satisfactory rate for goog drug encapsulation

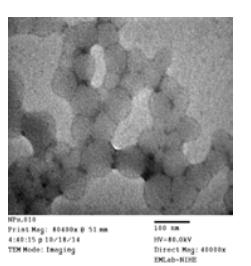

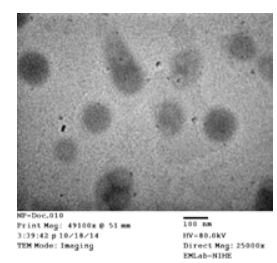

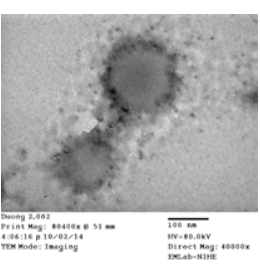

Figure 2: TEM images of NPs (A), Doc-NPs (B) and scFv-Doc-NPs derivetives (C).

\begin{tabular}{|l|c|c|c|c|}
\hline Samples & $\begin{array}{c}\text { Mean size } \pm \mathbf{S D} \\
\mathbf{( n m} \mathbf{)}\end{array}$ & PDI \pm SD & $\begin{array}{c}\text { Zeta potential } \pm \text { SD } \\
(\mathbf{m V})\end{array}$ & EE \\
\hline PLGA-PEG & $87 \pm 8$ & $0.08 \pm 0.02$ & $-24 \pm 0.3$ & \\
\hline Doc-PLGA-PEG & $105 \pm 4$ & $0.1 \pm 0.05$ & $-25 \pm 0.5$ & $43 \%$ \\
\hline $\begin{array}{l}\text { ScFv-Doc-PLGA- } \\
\text { PEG }\end{array}$ & $135 \pm 9$ & $0.1 \pm 0.07$ & $-32 \pm 1$ & \\
\hline
\end{tabular}

Table 1: Physicochemical characteristics of PLGA-PEG, Doc-PLGA-PEG and scFv-Doc-PLGA-PEG nanoparticles $(n=3)$.
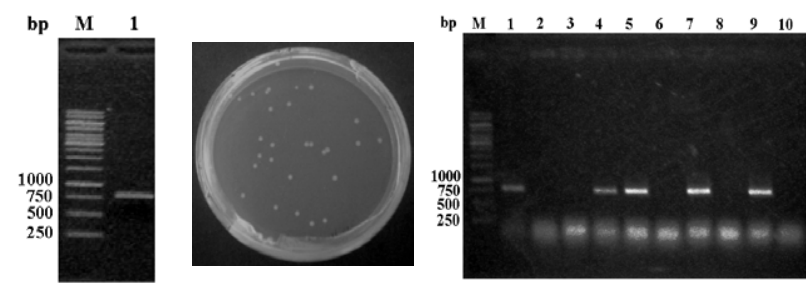

A B $\mathrm{C}$

Figure 3: The cloning and expression of $\mathrm{pET} 22 \mathrm{~b}(+)$ vector containing antiHER2 scFv gene in E. coli cells. 3A. Lane M: DNA marker $1 \mathrm{~kb}$ (Fermentas), lane 1: anti-HER2 scFv gene; 3B. E. coli clones; 3C. Lane M: DNA marker 1kb, lanes 1-10: anti-HER2 scFv gene analyzed by restriction enzymes from E. coli clones.

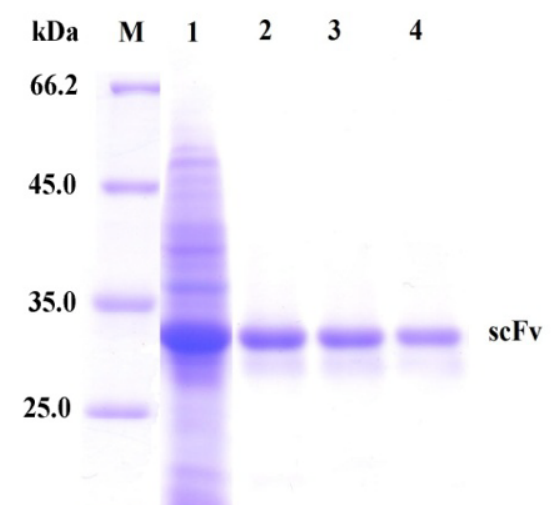

Figure 4: Purification of anti-HER2 scFv. 12.5\% SDS-PAGE confiming the purification of anti-HER2 scFv (31 kDa), CoomassieBrillian Blue R-25 stained gel; Lane M: Standard protein marker (Thermo Scientific); Lane 1: total protein of culture extract; Lane 2, 3 and 4: elution fractions ofscFv protein.

efficiency [41]. Table 1 also shows the drug loading efficiency and the PLGA-PEG nanoparticles prepared with nanoprecipitation method in this study resulted in a high drug encapsulation efficiency of $43 \%$.

\section{Results of expression and purification of anti-Her2 scFv}

The gene encoding anti-HER2 EDC scFv derived from a recombinant phage-display library (Griffin.1 library) have been screened, selected and registered on GeneBank (NCBI) with code AM402973.1 [42]. This gene was designed to fuse with His -tag on $C$-terminus and cloned by using forward 5'-GAGATATACAGAATTCCTGCCCTTAC-3' and reverse 5'-ATACAGCTCCCTCGAGTGAAGATACG-3' primers containing two EcoRI and $\mathrm{XhoI}$ restriction enzyme sites, respectively, a fragment of $800 \mathrm{bp}$ was produced by PCR (Figure 3A).

The PCR fragment was purified using the QIAGEN gel extraction kit and was ligated into pET22b(+) vector. pET22b(+) plasmids containing anti-HER2 EDC gene (pET22b(+)-EDC) were transfected in the Escherichia coli DH5a (E. coli DH5a) cells (Figure 3B). The recombinant clones were analyzed by restriction enzyme analysis (Figure 3C) and DNA sequencing.

Expression and purification of anti-HER2 scFv in E. coli were described in Materials and Methods. These anti-HER2 scFv antibodies were used as targeting molecules for directed delivery of Doc-loaded PLGA-PEG NPs to tumor cells. The proteins obtained were of the expected molecular weight and homogeneity according to SDS-PAGE (Figure 4).

\section{Flow cytometric analysis}

To test whether scFv-Doc-NPs would differentially bind to HER2-overexpress and HER2-underexpress cells, the binding of scFv-Doc-NPs to BT474 and MDA-MB-231 cells evaluated by FCM analysis. Previous studies have well established that BT474 cells are a human breast cancer cell line that overexpresses HER2 protein on its surface $\left(3.7 \times 10^{6}\right.$ receptors/cell $)$ and MDA-MB-231 cells are a HER2underexpress human breast cancer cell line $\left(7 \times 10^{4}\right.$ receptors/cell) [43]. Consistent with the original report, scFv-Doc-NPs demonstrated a higher binding to the BT474 cells than the MDA-MB-231 cells (Figure 5 ). The mean fluorescent intensity of scFv-Doc-NPs binding with BT474 cells is about 3 times higher than that with MDA-MB-231 cells. Since scFv may facilitate binding with the target. 

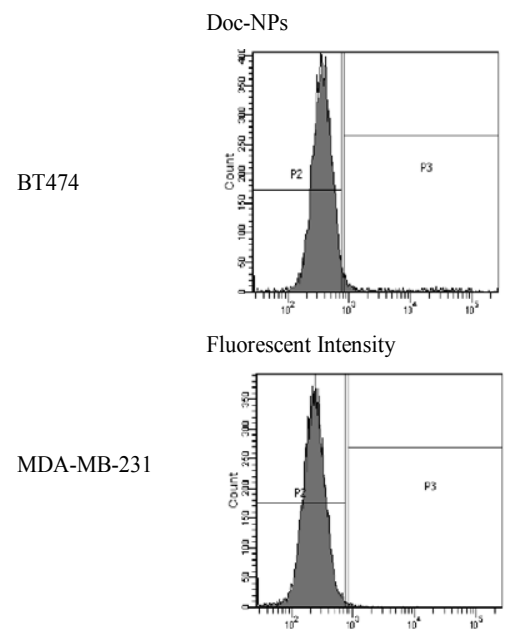

Fluorescent Intensity
Fluorescent Intensity

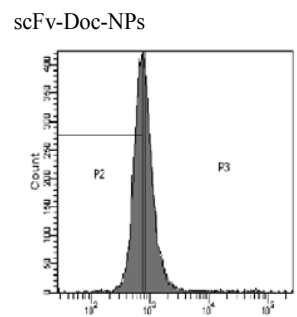

Fluorescent Intensity

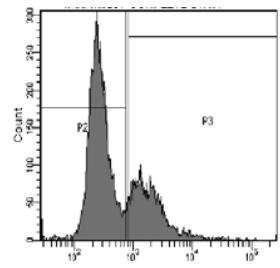

Fluorescent Intensity
Figure 5: FMC analysis of binding activity of HER2-overexpress BT474 and HER2-underexpress MDA-MB-231 cells treated with Doc-NPs solution as control and scFv-Doc-NPs derivative at RT for $30 \mathrm{~min}$ in PBS.

\section{Cellular uptake experiment}

To further explore the in vitro cancer targeting of scFv-Doc-NPs against the HER2-overexpressing cells, we perfomed in vitro cellular uptake studies with both BT474 and MDA-MB-231 cells using confocal fluorescence microscopy. The cells were incubated with antibodyconjugated or antibody-unconjugated nanoparticles as described and then fixed and detected the bound nanoparticles by indirect immunofluorescence by using mouse anti-histag primary antibody and Alexa 488-conjugated anti-mouse secondary antibody. Nuclei were counterstained with Hoechst. The results showed that scFvDoc-NPs generated enhanced fluorescence intensity in BT474 cells, comparing with MDA-MB-231 cells (Figure 6). Moreover, the images clearly indicated that the scFv-Doc-NPs were mainly accumulated in the cytoplasm of BT474 cells. Accordingly, scFv-Doc-NPs could be internalized into the BT474 cells and carry the anticancer drugs into the cytoplasm. Compared to BT474 cells, fluorescent signal of scFvDoc-NPs entered MDA-MB-231 cells was much less; suggesting again that the $\mathrm{scFv}$ facilitated the uptake of nanoparticles into the cells.

Figure 6: Confocal microscopy images of HER2-overexpress BT474 and HER2-underexpress MDA-MB-231 cells treated with DocNPs or scFv-Doc-NPs. The nuclei were stained with Hoechst. The merged images of Alexa 546 and the Hoechst channels. BT474 cells exposed to scFv-Doc-NPs at $100 \mu \mathrm{g} / \mathrm{ml}$ for $1 \mathrm{~h}$.

\section{In vitro cellular cytotoxicity assay}

A series of in vitro cytotoxicity assays was performed to evaluate the anticancer potential of free Doc, Doc-NPs, scFv-Doc-NPs using BT474 and MDA-MB-321 cells after an incubation of $72 \mathrm{~h}$ at $37^{\circ} \mathrm{C}$ (Figure 7). Anti-HER 2 scFv-unconjugated nanoparticles with no drug loading were also tested as negative control. Statistical analysis showed that the drug-unloaded and scFv-uncojugated nanoparticles did not influence on cell viability. Doc-NPs was highly cytotoxic for both BT-474 and MDA-MB-231 cells and they were also more toxic than free docetaxel. The $\mathrm{IC}_{50}$ values of free Doc and Doc-NPs were 1,55 and $0.69 \mu \mathrm{M}$ for BT474 cells and 1.61 and $0.80 \mu \mathrm{M}$ for MDA-MB-231 cells, respectively. However, the most cytotoxicity of scFv-Doc-NPs was in BT474 cells, while the cell toxicity of MDA-MB-231 cells was lower with $\mathrm{IC}_{50}$ values of 0.234 and $0.535 \mu \mathrm{M}$, respectively.

Moreover, the higher cytotoxicity of drug-entrapped NPs and targeted NPs can be due to different mechanisms between free drug molecules and various drug-loaded nanoparticle derivetives. Free drug molecules were transported into the cytoplasm by a passive diffusion and transported out by P-glycoprotein pumps. However, drug-loaded NPs penetrate into cells through the endocytosis and they can be escaped from the influence of P-glycoprotein pumps, resulting in a higher cellular uptake compared to free drug molecules [44]. Targeted delivery of nanoparticles can potentially enhance the selective killing of tumor cells. In this study, we utilized a anti-HER2 recombinant single chain $\mathrm{Fv}$ antibody fragment $(\mathrm{scFv})$ that bound specifically to extracellular domain of HER2 receptor and explored the therapeutic potential of anti-HER2 scFv-decorated pegylated PLGA nanoparticles. These targeted nanoparticles exhibited much improved cytotoxic activity compared to non-targeted nanoparticles in vitro. Thus, synergistic efficiency of the scFv-Doc-NP derivative can be explained

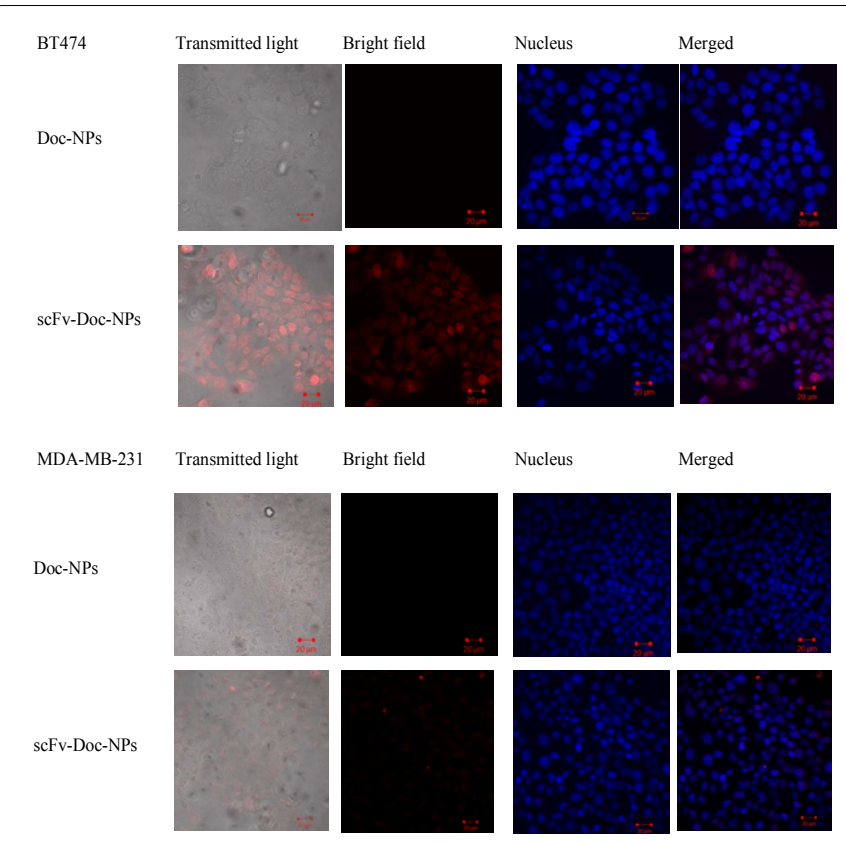

Figure 6: Confocal microscopy images of HER2-overexpress BT474 and HER2-underexpress MDA-MB-231 cells treated with Doc-NPs or ScFv-DocNPs. The nuclei were stained with Hoechst. The merged images of Alexa 546 and the Hoechst channels. BT474 cells exposed to scFv-Doc-NPs at $100 \mu \mathrm{g} /$ $\mathrm{ml}$ for $1 \mathrm{~h}$.
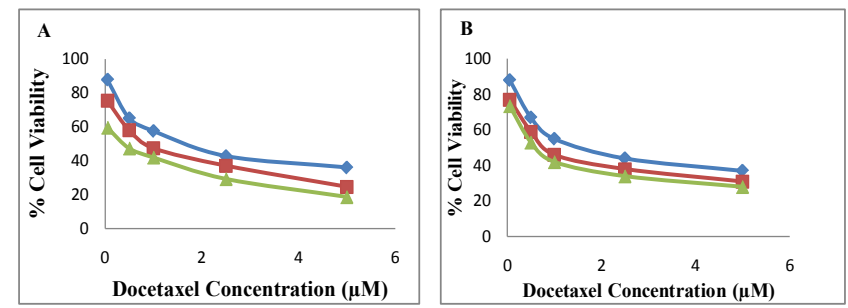

Figure 7: Cytotoxic effects of free Doc and Doc-NPs with or without antiHER2 scFv on target BT474 (A) and non-target MDA-MB-231 (B) cells. Cell viability was analyzed after incubation with different NPs and free Doc (equivalent docetaxelconcentrations $(0 \mu \mathrm{M}, 0.05 \mu \mathrm{M}, 0.5 \mu \mathrm{M}, 1 \mu \mathrm{M}, 2.5 \mu \mathrm{M}$, and $5 \mu \mathrm{M})$ of free Doc $(--)$, Doc-NPs $(--)$ and scFv-Doc-NPs $\left(-{ }_{-}\right)$using cytotoxicity assay Kit (MTT). 
by their specific interaction with HER2 antigens on the surface of BT474 cells, indicating the potential of these nanoparticles to treat human HER2-overexpression cancer cells. Conclusion

In this study, pegylated PLGA nanoparticles decorated with the novel anti-HER2 scFv suitable characterization were successfully prepared for targeted delivery of docetaxel in vitro. We have investigated binding and internalizing activity of anti-HER2 scFv-decorated pegylated PLGA nanoparticles using His -tag fused with novel antiHER2 scFv protein. The cytotoxic results of this targeting drug delivery system showed stronger cytotoxicity with BT474 cells than MDAMB-231 cells. The results suggest that great synergetic potential of scFv-Doc-NPs may have potential applications in targeted therapy against HER2-positive caner cells for further in vivo applications.

\section{Acknowledgment}

This work was supported by grants from State Program'Application-oriented basic scientific research' Project number: 04/2011/HĐ-NCCBUD and the part of grants from State Technological Science Program with Project number: KC.10.19/11-15 (Ministry of Science and Technology, Viet Nam). We are very grateful to PhD. Nguyen Thanh Tam for the analyzing support of ${ }^{1} \mathrm{H}$ nuclear magnetic resonance (NMR) of PLGA-PEG.

\section{References}

1. Yokoyama M (2005) Drug targeting with nano-sized carrier systems. J Artif Organs 8: 77-84

2. Zhang L, Radovic-Moreno AF, Alexis F, Frank XG, Pamela AB, et al. (2007) Co-Delivery of Hydrophobic and Hydrophilic Drugs from Nanoparticle-Aptamer Bioconjugates. Chem Med Chem 2: 1268-1271.

3. Mishra B, Patel BB, Tiwari S (2010) Colloidal nanocarriers: a review on formulation technology, types and applications toward targeted drug delivery. Nanomedicine 6: 9-24.

4. Brandt-Rauf PW, Pincus MR, Carney WP (1994 The c-erbB-2 protein in oncogenesis: molecular structure to molecular epidemiology. Crit Rev Oncogenesis 5: 313-329.

5. Yarden Y, Sliwkowski MX (2001) Untangling the ErbB signalling network. Nat Rev Mol Cell Biol 2: 127-137.

6. Meric F, Hung MC, Hortobagyi GN, Hunt KK (2002) HER2/neu in the management of invasive breast cancer. J Am Coll Surg 194: 488-501.

7. Koeppen HK, Wright BD, Burt AD, Quirke P, McNicol AM, et al. (2001) Overexpression of HER2/neu in solid tumours: an immunohistochemical survey. Histopathology 38: 96-104.

8. Mitri Z, Constantine T, O'Regan R (2012) The HER2 Receptor in Breast Cancer: Pathophysiology, Clinical Use, and New Advances in Therapy. Chemother Res Pract 2012: 743193.

9. Santin AD, Bellone S, Roman JJ, McKenney JK, Pecorelli S (2008) Trastuzumab treatment in patients with advanced or recurrent endometrial carcinoma overexpressing HER2/neu. Int J Gynaecol Obstet 102: 128-131.

10. Krauss J (2003) Recombinant antibodies for the diagnosis and treatment of cancer. Mol Biotechnol 25: 1-17

11. Ackerson CJ, Jadzinsky PD, Jensen GJ, Kornberg RD (2006) Rigid, specific, and discrete gold nanoparticle/antibody conjugates. J Am Chem Soc 128 2635-2640.

12. Kirpotin DB, Drummond DC, Shao Y, Shalaby MR, Hong K, et al. (2006) Antibody Targeting of Long-Circulating Lipidic Nanoparticles Does Not Increase Tumor Localization but Does Increase Internalization in Animal Models. Cancer Res 66: 6732-6740.

13. Hoogenboom HR1 (2005) Selecting and screening recombinant antibody libraries. Nat Biotechnol 23: 1105-1116.

14. Cho K, Wang X, Nie S, Chen ZG, Shin DM (2008) Therapeutic nanoparticles for drug delivery in cancer. Clin Cancer Res 14: 1310-1316.

15. Algar WR, Prasuhn DE, Stewart MH, Jennings TL, Blanco-Canosa JB, et al. (2011) The controlled display of biomolecules on nanoparticles: a challenge suited to bioorthogonal chemistry. Bioconjug Chem 22: 825-858.
16. Athanasiou KA, Niederauer GG, Agrawal CM (1996) Sterilization, toxicity, biocompatibility and clinical applications of polylactic acid/polyglycolic acid copolymers. Biomaterials 17: 93-102.

17. Makadia HK, Siegel SJ (2011) Poly Lactic-co-Glycolic Acid (PLGA) as Biodegradable Controlled Drug Delivery Carrier. Polymers (Basel) 3: 1377 1397.

18. Dinarvand R, Sepehri N, Manoochehri S, Rouhani H, Atyabi F (2011) Polylactide-co-glycolide nanoparticles for controlled delivery of anticancer agents. Int J Nanomedicine 6: 877-895.

19. Gupta AK, Naregalkar RR, Vaidya VD, Gupta M (2007) Recent advances on surface engineering of magnetic iron oxide nanoparticles and their biomedical applications. Nanomedicine (Lond) 2: 23-39.

20. Bailon P, Won CY (2009) PEG-modified biopharmaceuticals. Expert Opin Drug Deliv 6: 1-16.

21. Park JW, Hong K, Kirpotin DB, Colbern G, Shalaby R, et al. (2002) Anti-HER2 immunoliposomes: enhanced efficacy attributable to targeted delivery. Clin Cancer Res 8: 1172-1181.

22. Wang H, Zhao $\mathrm{Y}, \mathrm{Wu} \mathrm{Y}, \mathrm{Hu} \mathrm{YL}$, Nan K, et al. (2011) Enhanced anti-tumo efficacy by co-delivery of doxorubicin and paclitaxel with amphiphilic methoxy PEG-PLGA copolymer nanoparticles. Biomaterials 32: 8281-8290.

23. Noori Koopaei M, Khoshayand MR2, Mostafavi SH3, Amini M4, Khorramizadeh MR5, et al. (2014) Docetaxel Loaded PEG-PLGA Nanoparticles: Optimized Drug Loading, In-vitro Cytotoxicity and In-vivo Antitumor Effect. Iran J Pharm Res 13: 819-833.

24. Alibolandi M, Ramezani M, Sadeghi F, Abnous K, Hadizadeh F (2015) Epithelia cell adhesion molecule aptamer conjugated PEG-PLGA nanopolymersomes for targeted delivery of doxorubicin to human breast adenocarcinoma cell line in vitro. Int J Pharm 479: 241-251.

25. Li L, Xiang D, Shigdar S, Yang W, Li Q, et al. (2014) Epithelial cell adhesion molecule aptamer functionalized PLGA-lecithin-curcumin-PEG nanoparticles for targeted drug delivery to human colorectal adenocarcinoma cells. Int $J$ Nanomedicine 9: 1083-1096

26. Shirode AB, Bharali DJ, Nallanthighal S, Coon JK, Mousa SA, et al. (2015) Nanoencapsulation of pomegranate bioactive compounds for breast cancer chemoprevention. Int J Nanomedicine 10: 475-484

27. Cirstoiu-Hapca A, Bossy-Nobs L, Buchegger F, Gurny R, Delie F (2007) Differential tumor cell targeting of anti-HER2 (Herceptin) and anti-CD20 (Mabthera) coupled nanoparticles. Int J Pharm 133: 190-196.

28. Cirstoiu-Hapca A, Buchegger F, Bossy L, Kosinski M, Gurny R, et al., (2009) Nanomedicines for active targeting: physic-chemical characterization of paclitaxel-loaded anti-HER2 immunonanoparticles and in vitro functional studies on target cells. Eur J Pharm Sci 38: 230-237.

29. Hussain AF, Krüger HR, Kampmeier F, Weissbach T, Licha K, et al. (2013) Targeted delivery of dendritic polyglycerol-doxorubicin conjugates by scFvSNAP fusion protein suppresses EGFR+ cancer cell growth. Biomacromolecules 14: $2510-2520$.

30. Esmaeili $F$, Dinarvand $\mathrm{R}$, Ghahremani $\mathrm{MH}$, Amini $\mathrm{M}$, Rouhani $\mathrm{H}$, et al. (2009) Docetaxel-albumin conjugates: preparation, in vitro evaluation and biodistribution studies. J Pharm Sci 98: 2718-2730.

31. Esmaeili F, Dinarvand R, Ghahremani MH, Ostad SN, Esmaily H, et al. (2010) Cellular cytotoxicity and in-vivo biodistribution of docetaxel poly(lactide-coglycolide) nanoparticles. Anticancer Drugs 21: 43-52.

32. Saremi S, Atyabi F, Akhlaghi SP, Ostad SN, Dinarvand R (2011) Thiolated chitosan nanoparticles for enhancing oral absorption of docetaxel: preparation, in vitro and ex vivo evaluation. Int J Nanomedicine 6: 119-128.

33. Ueda M, Hisada H, Temma T, Shimizu Y, Kimura H, et al. (2015) Gallium68-Labeled Anti-HER2 Single-Chain Fv Fragment: Development and In Vivo Monitoring of HER2 Expression. Mol Imaging Biol 17: 102-110.

34. Hussain AF, Krüger HR, Kampmeier F, Weissbach T, Licha K, et al., (2013) Targeted delivery of dendritic polyglycerol-doxorubicin conjugates by scFvSNAP fusion protein suppress EGFR+ cancer cell growth. Biomacromolecules 14: $2510-2520$.

35. Lu RM, Chang YL, Chen MS, Wu HC (2011) Single chain anti-c-Met antibody conjugated nanoparticles for in vivo tumor-targeted imaging and drug delivery. Biomaterials 32: 3265-3274. 
Citation: Le DTT, Dang LTM, Hoang NTM, La HT, Nguyen HTM, et al. (2015) Anti-Tumor Activity of Docetaxel PLGA-PEG Nanoparticles with a Novel Anti-HER2 scFv. J Nanomed Nanotechnol 6: 267. doi:10.4172/2157-7439.1000267

36. Steinhauser I, Spa B, Strebhardt K, Langer K (2006) Trastuzumab-modified nanoparticles: Optimisation of preparation and uptake in cancer cells. Analysis 27: 4975-4983.

37. Hobbs SK, Monsky WL, Yuan F, Roberts WG, Griffith L, et al. (1998) Regulation of transport pathways in tumor vessels: role of tumor type and microenvironment. Proc Natl Acad Sci USA 95: 4607-4612.

38. Ishida O, Maruyama K, Sasaki K, Iwatsuru M (1999) Size-dependent extravasation and interstitial localization of polyethyleneglycol liposomes in solid tumor-bearing mice. Int J Pharm 190: 49-56.

39. Suh H, Jeong B, Rathi R, Kim SW (1998) Regulation of smooth muscle cell proliferation using paclitaxel-loaded poly(ethylene oxide)-poly(lactide/glycolide) nanospheres. J Biomed Mater Res 42: 331-338.

40. Dong Y, Feng SS (2004) Methoxy poly(ethylene glycol)-poly(lactide) (MPEGPLA) nanoparticles for controlled delivery of anticancer drugs. Biomaterials 25 : 2843-2849.
41. Cheng J, Teply BA, Sherifi I, Sung J, Luther G, et al. (2007) Formulation of functionalized PLGA-PEG nanoparticles for in vivo targeted drug delivery. Biomaterials 28: 869-876.

42. Le QH, Nguyen TTD, La TH, Tran TTH, Nguyen TTT (2013) Viet Nam Patent Application.

43. Hathaway HJ, Butler KS, Adolphi NL, Lovato DM, Belfon R, et al. (2011) Detection of breast cancer cells using targeted magnetic nanoparticles and ultra-sensitive magnetic field sensors. Breast Cancer Res 13: R108.

44. Panyam J, Labhasetwar V (2003) Dynamics of endocytosis and exocytosis of poly(D,L-lactide-co-glycolide) nanoparticles in vascular smooth muscle cells. Pharm Res 20: 212-220.

45. Le TTD, La TH, Le TMP, Pham VP, Nguyen TMH, et al. (2013) Docetaxel and curcumin-containing poly(ethylene glycol)-block-poly(e-caprolactone) polymer micelles. Adv Nat Sci: Nanosci Nanotechnol 4: 025006. 